REVISTA CIENCIAS BIOMÉDICAS

ÉTICA, BIOÉTICA Y HUMANISMO

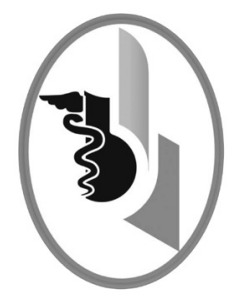

\title{
iOH, ETERNA MEDICINA, ¿POR QUÉ DESPOJAN TU ESENCIA?!
}

\author{
OH, ETERNAL MEDICINE, WHY ARE YOU BEING STRIPPED \\ OF YOUR ESSENCE?
}

Olivera-Díaz Álvaro ${ }^{1}$

Correspondencia: aoliverad1@unicartagena.edu.co

Recibido para evaluación: marzo-12-2016. Aceptado para publicación: octubre-14-2016

\section{RESUMEN}

A pesar de las normas legales existentes, la práctica histórica de la medicina centrada en el paciente y motivada por el mejor interés en función de la salud y superación de la enfermedad como necesidad, se está difuminando y requiere dolientes que avizoren horizontes de urgente solución para mantenerse visible. En términos generales podría decirse que muy pocos están exentos de padecer por los pesares que afectan a la medicina y su ejercicio, por lo que actores que intervienen en su valorado mundo encuentran razones para sentirse afectados. Es improbable que alguien pueda excluirse de ser actor principal, porque el hecho de ser seres finitos y vulnerables ante la contingencia de la enfermedad reivindica el papel potencial de actores sujetos del conocimiento médico substrato de la medicina. Hoy está en riesgo de amenaza su práctica tradicional de servicio por los desatinos mercantilistas de una política sanitaria que luce indecente; el clamor general por su restablecimiento está presente y la ciudadanía reclama políticas idóneas e instrumentos prácticos de justicia sanitaria que la medicina en su contexto general merece. El propósito es identificar los mayores signos que afectan el ejercicio de la medicina, con el ánimo de convocar acciones de índole estatal en materia política, profesional y ciudadana que permitan superarlos en procura del bien preciado de la salud. Rev.cienc.biomed. 2016;7(2):360-366.

PALABRAS CLAVE

Enfermedad; Medicina; Prestación de Atención de Salud.

1 Médico. Pediatra. Especialista en Educación Médica. Gerencia en Salud. Magíster en Bioética. Profesor Asociado. Jefe Departamento de Bioética. Facultad de Medicina. Universidad de Cartagena. Colombia. 


\title{
SUMMARY
}

\begin{abstract}
Despite existing legal norms, the historical practice of medicine centered in the patient and motivated by the best interest in health, and overcoming the disease as a necessity is becoming blurred and requires mourners who see horizons of urgent solution to stay visible. In general terms, it could be said that very few are exempt from suffering because of the regrets that affect medicine and its exercise, so that actors who intervene in their valued world find reasons to feel affected. It is unlikely that anyone can be excluded from being a principal actor, because being finite and vulnerable in the face of the contingency of disease claims the potential role of subject actors of medical knowledge substrate of medicine. Today is at risk of threat its traditional practice of service by the mercantilist follies of a sanitary policy that looks indecent; the general clamor for its reestablishment is present and the citizenry demands suitable policies and practical instruments of sanitary justice that medicine in its general context deserves. The purpose is to identify the major signs that affect the practice of medicine, with the aim of summoning actions of a state nature in political, professional and citizen matters that allow them to overcome them in pursuit of the precious good of health. Rev.cienc. biomed. 2016;7(2):360-366.
\end{abstract}

KEYWORDS

Disease; Medicine; Delivery of Health Care.

\section{INTRODUCCIÓN}

Un respetado profesor de humanidades médicas en la Universidad de Cartagena expresaba al dirigirse a los neófitos: "El médico es el padre de la sociedad". Así lo intuyó, destacando el valor de quienes inscribieron el saber médico en los conocimientos científicos desde la antigüedad. La medicina, y quienes la profesaban, representaban el bien común, donde las retribuciones por las buenas acciones se simbolizaban en honores. Eran épocas de inmunidad jurídica para el profesional. Las visiones del bien amparadas en el derecho moral y el legado de Hipócrates eran motivos suficientes para creer y confiar. La tradición del principio de moralidad fundada en ese orden sostenía el paradigma del derecho natural basado en la racionalidad del buen ser y del bien hacer, pero el desarrollo de los tiempos y quienes disentían por la vigencia de ese lineamiento moral encontraron fundamentos que dieron lugar a un modelo de decisión moral basado en el contrato social.

Con ese referente, pero rezagados por la brecha del tiempo, el pensamiento liberal en el devenir histórico hizo posible muchos avances, pero los poderes colonialistas asentados en el territorio patrio desatendían esa fuente inspiradora del contrato social y todo indica que omitieron las bondades del bien común e idearon modelos de contrato social no extensivos a un bienestar general, desatendiendo la evolución histórica de un modelo de justica que abogaba por la primacía de derechos negativos como antesala a la instauración de los derechos sociales positivos conectados con un futuro de bienestar colectivo. Tanto desde el punto de vista formal como material, la justicia se insinuaba excluida, cuando esta debe ser principio rector del orden social. En términos sociales, la medicina siempre ha sido una de las más preciadas prácticas.

En ese orden, de la percepción y narrativa histórica se infiere que en Colombia la desatención material por la justicia sigue vigente y afecta prácticas que siempre han estado al servicio del bienestar social: una de esas es la medicina. El altruismo médico que tanto pudo resistir, finalmente está enfermo, pero, ¿cuáles serían los factores incidentes? Se formulan cuatro hipótesis.

\section{[1]. La visión economicista de la política sanitaria}

La tradición médica occidental subyace per se en el concepto de beneficencia. Milenariamente el prestador sanitario profesaba acciones análogas a las descritas en la parábola del buen samaritano. Esos códigos no escritos de moral profesional expresados en 
lex artis coinciden con el respeto al derecho moral de la salud y se remontan con el arquetipo de Hipócrates. Esa tradición estaba consagrada en Colombia hace décadas con el ejercicio sanitario basado en un modelo de estado benefactor que subsidiaba la oferta pública sanitaria, aunque con las consabidas debilidades en la cobertura y acceso poblacional alentadas por los vicios de una precaria e inmoral administración política de la salud pública. El panorama nacional con debilidades administrativas crecientes y las exigencias de los organismos de la banca internacional en materia de política neoliberal alentaron la labor de los poderes públicos para inspirarse en modelos económicos que desatendían la función social del Estado, creando mecanismos legales que subsidiaban la demanda con la participación de actores privados representados en EPS (empresas promotoras de salud) y conjuntamente con la supervisión estatal asumían funciones análogas al aseguramiento y prestación sanitaria.

Esa transformación creó legalmente la intermediación utilitaria, dando margen a sesgos economicistas en detrimento de los propósitos por una práctica social de la medicina para con los afectados. Las decisiones ya no dependían autónomamente de los códigos morales del profesional sanitario que veía en el paciente el propósito de sus acciones, sino también del gestor inversionista que procuraba el buen ejercicio económico de la institución aseguradora o prestadora que representaba. Esto traduce una ambigüedad que afecta el buen ejercicio de la práctica en medicina. El profesional médico, quizá con la mayor escolaridad profesional del país, tácitamente fue obligado a sustituir su moral profesional despojada de los tiempos de atención autónomos en detrimento de la calidad en el servicio ante el volumen de la demanda asistencialista subsidiada, transformándose de profesional en "obrero de estetoscopio".

Pero hay que considerar que, a pesar de una dimensión de servicios representada en un modelo institucional solidario que satisface teóricamente demandas e intereses en salud de los afectados, se cuestiona materialmente el papel de las EPS por las discrepancias en el amparo de las necesidades de salud y asistencia sanitaria: una ola de incertidumbre económica está presente en las IPS (instituciones prestadoras de salud), por el desequilibrio entre los costos de la atención no compensados con la reciprocidad del ingreso. Esa lógica económica incumplida de las instituciones se traslada a la práctica de la medicina. Entretanto, la sociedad cuestiona el ineficaz papel de supervisión y falta de garantías por parte del Estado. Allí subyace la ambigüedad del modelo económico de política sanitaria: los mecanismos de modulación y supervisión obligan al asegurador y al prestador a honrar la asistencia sanitaria debida, pero no es garante de un mecanismo de control de los recursos que permita a las instituciones obtener la retribución del esfuerzo y de los costos del servicio. Esto es, las instituciones médicas prestadoras cumplen con servir, pero no tienen garantizado el retorno oportuno de la inversión consumida en la prestación, generando iliquidez e insatisfacción general.

Éticamente, las inversiones de aseguradores y prestadores sanitarios no deberían reñir con el criterio del beneficio, porque moralmente la medicina y la profesión sanitaria están inscritas como actividades y prácticas sociales sin ánimo de lucro. Y un estado mínimamente decente no debe permitir que se sustituya la tradición ética de la asistencia sanitaria por el lucro, al delegarla en instituciones utilitarias que mediante la intermediación rentista procuran dividendos económicos que lesionan la intención benéfica de la medicina y la práctica médica.

Ante la amenaza derivada de la política sanitaria de perfil mercantilista vigente, es obligación moral de las profesiones sanitarias, de la ciudadanía y la sociedad defender ante las autoridades del Estado la tradición y pureza moral de la práctica médica para un buen ejercicio de la medicina en función del bien común. Esa postura supone transformaciones sustanciales en materia de política sanitaria para que sea asumida directamente por el Estado y que conlleven a un justo sistema sanitario donde se rescate la tradición ética médica que siempre verá en el beneficio del paciente el propósito de la profesión. 


\section{[2]. La visión asistencialista de la política sanitaria}

Del saber popular surge la expresión: "Es mejor prevenir que curar". Y en el antológico documental Sicko de Michael Moore, se presenta la realidad de varios sistemas de asistencia sanitaria de Occidente que son justos y sostenibles, y en la mirada de quienes ofician de administradores, ejecutores y beneficiarios, la medicina preventiva es pilar del buen funcionamiento y sostenibilidad del sistema. En esos sistemas públicos y unificados, el cuidador sanitario es mejor retribuido cuanto más participe disminuyendo la incidencia de la enfermedad. Menos enfermos en virtud a labores de educación y prevención, mayor ingreso para el profesional y cuidador sanitario. "Early intervention" es la clave, expresaba coloquialmente una colombiana oficiante de cuidados en el sistema de salud británico.

Pero, ¿por qué nuestro sistema sanitario se encuentra en las antípodas de la prevención?

De acuerdo con Diego Gracia hay que considerar dos momentos en un sistema justo de salud: deontológico y teleológico. Según este, la bondad de los actos que procuran proteger la salud y fomentar la asistencia sanitaria mediante el cuidado debido, se evalúan moralmente por las consecuencias. A partir de esa premisa, el observador común puede inferir que ni lo uno, ni lo otro se está haciendo debidamente en Colombia. Se percibe que no se están cumpliendo los deberes. En primer lugar, porque operativamente se confunde el concepto de salud con el de asistencia sanitaria. En términos prácticos, lo primario y esencial para la medicina es procurar y mantener el estado de salud, así, la salud se convierte en un bien preciado de producción, pero se aprecia que las cosas no funcionan de esa manera en materia de política sanitaria, puesto que lo que es visible y prioritario es la asistencia o los intentos de asistencia debida, en tanto que la protección de la salud es difícil de identificar.

Es como si la protección de la salud mediada por la higiene, el saneamiento ambiental, educación y prevención, y estilos de vida saludable no crearan imagen de servicio público; los abordajes a menudo poco diligentes y acelerados van en detrimento del valor humanístico de la medicina. Se materializa en incentivar y privilegiar la asistencia en perjuicio de la educación y la prevención, y, por supuesto, que ambas dimensiones se necesitan. No obstante, parece que los tiempos en función de la educación en salud no hicieran parte de la lógica sanitaria, por cuanto se subestima la forma en que operan esas temporalidades.

En segundo lugar, para la OMS (Organización Mundial de la Salud) la salud no es solo la ausencia de enfermedad. Si se apela al sentido común, salud es un concepto integral; es primariamente el bien que se ha de producir; es el núcleo de un derecho a no ser sujeto de una acción lesiva que la afecte derivada del Estado o de terceros, así como también una responsabilidad individual que se gestiona mediante el autocuidado. Alrededor de esas consideraciones ha evolucionado históricamente el concepto de salud desde Hipócrates, y en época reciente se habla de factores determinantes, que a partir del año 1974, encontraron en el entonces ministro de salud canadiense Marc Lalonde, la formulación de campos de salud representados en cuatro factores: biología humana, medio ambiente, estilo de vida, y sistema sanitario.

Se ha demostrado que las acciones preventivas orientadas a mantener un medio ambiente sano y el fomento de estilos de vida saludables son más costo-efectivos en relación con la infraestructura asistencialista de servicios sanitarios. En contraposición, los hábitos consumistas inmoderados y los desórdenes administrativos de control ambiental que permiten las prácticas contaminantes del aire y fuentes hídricas conspiran contra el bien de producción de la salud y entorpecen el interés primario de la medicina orientado hacia el bienestar común.

\section{[3]. El modelo de educación médica}

La historia de la medicina contemporánea permite comprender los estrechos vínculos de la educación médica occidental durante 
el siglo XX con la influencia del Informe de Abraham Flexner, encomendado especialmente por las Fundaciones Carnegie y Rockefeller, en 1910 en Estados Unidos, a través del cual se inspira la generación de transformaciones en la medicina científica con la aparición del ordenamiento académico de las disciplinas médicas que han incidido en el desarrollo del modelo pedagógico y asistencial de la medicina.

Con la aparición y el fortalecimiento de las especialidades médicas visibles desde mediados del siglo XX se asistía a un modelo biomédico que significaba una transición hacia lo que sería el debilitamiento en lo resolutivo de la medicina general, esta se fundamentaba en la asistencia personalizada que carecía de elementos tecnológicos, y se respaldaba en la habilidad clínica y en el ejercicio empírico como legado de una tradición pedagógica conductista propia de la época.

A pesar de las transformaciones de la medicina con el influjo de las tecnociencias, se ha cuestionado la influencia del informe Flexner por las introducciones metodológicas asignaturistas y reduccionistas para el aprendizaje de la medicina, amén de los conflictos de interés que abrieron las puertas a la mercantilización utilitaria con el surgimiento de la industria farmacéutica, y la sustitución de formas tradicionales de medicina útiles que incidieron en la medicalización de la sociedad.

Aunque no se conocen estudios que hayan evaluado puntualmente la calidad de la educación médica y capacidad resolutiva de los médicos generalistas, autoridades en educación médica como el doctor Fernando Sánchez Torres expresan sus temores: (...) En los sectores académico y gremial de la profesión hay preocupación por la falta de preparación de buena parte de los nuevos médicos que semestralmente son lanzados al mercado; pues no son garantía para la sociedad a la que van a servir.

Asimismo, existe la proliferación en las últimas décadas de facultades de medicina, algunas no acreditadas, otras sí, y con matrículas que reflejan en sus costos el interés rentista de quienes ofertan educación. Y qué decir del escenario asistencial de crisis hospitalaria recurrente por la complejidad administrativa propia del actual modelo sanitario, y de las instituciones clínicas que a pesar de los teóricos indicadores de calidad en los ambientes de aprendizaje para acceder a prácticas formativas concurren estudiantes de diferentes facultades de medicina a una misma institución sanitaria, compitiendo expresamente por espacios académicos y exponiendo el cumplimiento de esos indicadores expresados en la normatividad vigente por las pretensiones de los registros calificados o por la acreditación de calidad.

Esa extraña dualidad en la calidad de la educación médica expresada en instituciones con registro calificado y otras con acreditación supone que algunas están en el piso y otras en la cúspide de la calidad del servicio educativo que ofertan. No hay una justificación racional que explique esa calificación entre instituciones, pues si se trata de una diferencia en la calidad, la misma se traslada a la prestación de la atención médica y esa discrepancia riñe con los principios de un ejercicio ético en la medicina.

\section{[4]. La erosión general de valores morales y éticos}

En su libro El mundo de los valores, la autora española Adela Cortina señala que: "En los últimos tiempos se ha puesto de moda hablar de la educación en valores. Se multiplican los cursos, las jornadas y los artículos sobre el tema".

Sin duda, existe interés universal por los valores y hay que empezar por el principio: hogar, escuela, entorno social, universidad, sociedad, Estado. En medicina: icuánta nostalgia por el despojo de los valores morales y éticos! Las preocupaciones sobre la percepción de situaciones no éticas en el escenario clínico, y cómo las mismas afectan o modifican el código de ética personal del futuro médico. Sin embargo, son pocos los estudios que han intentado evaluar cómo los estudiantes de Medicina perciben su ambiente ético y el impacto que este ejerce en su desarrollo moral. 
En uno de esos pocos estudios se demostró que los estudiantes de medicina observan cómo participan en conductas no éticas comenzando tempranamente en los primeros años de estudios, cuestionándose la influencia de esa exposición sobre el sistema de valores de los estudiantes. Otro estudio revela dos fenómenos interesantes: primero, los potenciales efectos de exposición a situaciones no éticas como los comentarios inapropiados acerca de la situación de los pacientes; segundo, una paradoja ética: los estudiantes de medicina observan y aún participan en conductas no éticas, sin embargo, la mayoría sostiene que su código personal de ética no cambiará. Esto contrasta con los resultados encontrados por el estudio de Feudtner et al., en el cual el $62 \%$ de los estudiantes de tercero y cuarto año sometidos a la exposición de comentarios inapropiados acerca de los pacientes mostraron una gradual erosión ética en el curso del tiempo.

Cómo afecta esa situación la relación médica con el paciente y por supuesto, a la medicina, es temática tratada por el autor James Drane, a propósito del ensayo escrito por Oliver Sacks El hombre que confundió a su esposa con un sombrero, para aludir a la medicina altamente técnica y científica que sustituye al enfermo por la enfermedad y medicaliza a la sociedad olvidándose del individuo. A su vez, la sociedad reacciona y no distingue las buenas intenciones que caracterizan al buen médico de los riesgos previstos en la práctica médica; convirtiéndolos en hechos noticiosos que sustituyen la licitud del acto médico y cuestionan los valores éticos e idoneidad del profesional sanitario, generando desconfianza social con desprestigio moral del médico. La pérdida de confianza suscita tensiones en la relación médico-paciente que afectan el buen ejercicio, porque la confianza como virtud "es el cemento que une a la sociedad" y asistimos a una crisis social progresiva de esa virtud que conlleva serios problemas éticos en la práctica de una medicina indefensa, donde la interacción médico-paciente se convierte en un síndrome, metafóricamente descrito por el profesor Mario Mendoza, inspirado en la obra Memorias de Adriano y las analogías con el sistema sanitario en Colombia.

\section{CONCLUSIÓN}

Existe un rito ceremonial heredado de la tradición médica occidental que proviene de Hipócrates, padre de la medicina, basado en el razonamiento práctico de la ética y el método clínico constitutivos de su impronta moral, convencionalmente plasmado en norma legal como instrumento de convivencia en las relaciones de práctica profesional entre colegas, pacientes, sociedad y Estado. No obstante, entre la solemnidad de las buenas intenciones se mencionan cuatro hechos que conspiran cotidianamente contra el sano ejercicio de la medicina y su práctica profesional. Estos se constituyen en barreras afectan y lesionan la esencia de la labor médica. Superar estas imperfecciones trasciende la capacidad del ejercicio profesional, porque residen en la estructura de la política sanitaria, convirtiéndose en temática de dominio público que convoca la participación de poderes hacia el reencuentro con un sistema sanitario decente que garantice oportunidades en el marco de un modelo de justicia con bienestar colectivo bajo la custodia del Estado, exento de intereses mercantilistas por la avaricia del inversor y coherente con el ejercicio libre y autónomo de la medicina.

CONFLICTO DE INTERESES: ninguno que declarar.

FINANCIACIÓN: Universidad de Cartagena.

\section{LECTURAS RECOMENDADAS}

1. Almond B. Los derechos. Compendio de ética. Singer P. (ed.) Madrid 1993.

2. Buckle S. El derecho natural. Compendio de ética. Singer P (ed). Madrid 1993.

3. Beauchamp T, Childress J. Principles of biomedical ethics. Seventh Edition. Oxford University Press. 2012.

4. Cortina A. El mundo de los valores. Bogotá D.C. 1997.

5. Drane JF. Cómo ser un buen Médico. 1998, Bogotá D.C.

6. Gracia D. Profesión médica, investigación y justicia sanitaria. Bogotá.1998. 
7. Guzmán De, Cum-Laude M. Ley Estatutaria de salud (Ley 1751 de 2015). Gaceta Jurisprudencial. Tribunal Nacional de Ética Médica. Abril 2015.

8. Mendoza M. Patogenia del síndrome de Hermógenes. Descripción del síndrome de Adriano. Acta Médica Colombiana 1999;24(2):60-65.

9. Olivera A. El devenir en educación médica: un encuentro con la bioética. Revista Salud Uninorte. 2010;26(2):349-359.

10. Petit P. El consecuencialismo. Compendio de ética. Singer P. (ed). Madrid 1993.

11. Rawls J. Teoría de la Justicia. México 2010.

12. Simón-Lorda P. Ética de las organizaciones sanitarias. Madrid 2005.

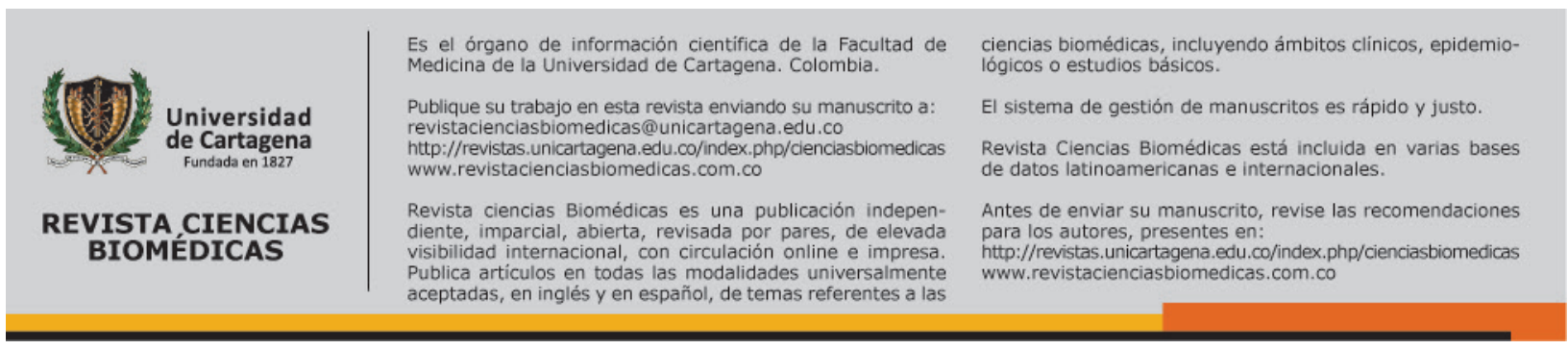

